This item was submitted to Loughborough's Research Repository by the author.

Items in Figshare are protected by copyright, with all rights reserved, unless otherwise indicated.

\title{
Use of supramolecular assemblies as lithographic resists
}

PLEASE CITE THE PUBLISHED VERSION

https://doi.org/10.1002/anie.201700224

PUBLISHER

(c) Wiley

VERSION

AM (Accepted Manuscript)

\section{PUBLISHER STATEMENT}

This work is made available according to the conditions of the Creative Commons Attribution-NonCommercialNoDerivatives 4.0 International (CC BY-NC-ND 4.0) licence. Full details of this licence are available at: https://creativecommons.org/licenses/by-nc-nd/4.0/

\section{LICENCE}

CC BY-NC-ND 4.0

\section{REPOSITORY RECORD}

Lewis, Scott M., Antonio Fernandez-Mato, Guy A. DeRose, Matthew S. Hunt, George F. Whitehead, Agnese Lagzda, Hayden R. Alty, et al.. 2017. "Use of Supramolecular Assemblies as Lithographic Resists". Loughborough University. https://hdl.handle.net/2134/37379. 


\title{
Use of Supramolecular Assemblies as Lithographic Resists
}

\author{
Scott M. Lewis ${ }^{[a]}$, ${ }^{*}$ Antonio Fernandez ${ }^{[a]}$, Guy A. DeRose ${ }^{[b]}$, Matthew S. Hunt ${ }^{[b]}$, George F. S. \\ Whitehead ${ }^{[a]}$, Agnese Lagzda ${ }^{[a]}$, Hayden R. Alty ${ }^{[a]}$, Jesus Ferrando-Soria ${ }^{[a]}$, Sarah Varey ${ }^{[a]}$, Andreas K. \\ Kostopoulos $^{[a]}$, Fredrik Schedin ${ }^{[c]}$, Christopher A. Muryn ${ }^{[a]}$, Grigore A. Timco ${ }^{[a]}$, Axel Scherer ${ }^{[b]}$, Stephen \\ G. Yeates ${ }^{[a]}$ and Richard E. P. Winpenny ${ }^{\left[{ }^{[a]} *\right.}$
}

Abstract: We show that by design we can create a new resist materials for electron beam lithography, based on a supramolecular assembly. The initial studies show that via this supramolecular approach high resolution structures can be written which show unprecedented selectivity when exposed to etch conditions involving plasmas.

Supramolecular chemistry has reached a major landmark with the award of the 2016 Nobel Prize for work on molecular machines. ${ }^{1}$ There are remarkably imaginative and potentially transformative proposals to use supramolecular chemistry, for example as components of memory devices, ${ }^{2}$ or as molecular robots to assemble small peptides, ${ }^{3}$ or as rotary motors powered with light, ${ }^{4}$ or as supramolecular spin valves. ${ }^{5}$ Real-world applications of this branch of nanoscience will only appear in the future.

The major technological advances in nanoscience to this point have arisen from the fabrication by lithography of integrated circuits (ICs). The main component of an IC is a field effect transistor (FET) and the reduction in size of FETs has led to a revolution in electronics over the last five decades. The sizelimiting fabrication step is lithography, which involves writing a pattern into a resist material prior to etching. ${ }^{6}$ Conventional resist materials are organic polymers such as polymethylmethacrylate (PMMA). ${ }^{7}$ The technological roadmap in electronics ${ }^{8}$ requires still further reduction in the size of FETs and drives massive investment in lithographic equipment. New resists are therefore needed and materials studied include co-polymer and block copolymers, hydrogen silsesquioxane (HSQ), ${ }^{9}$ fullerenes, ${ }^{10}$ composites ${ }^{11}$ and metal-oxide films. ${ }^{12}$ There remains a huge scope for further advances based on design, and we wondered whether supramolecular chemistry could make a contribution in designing resist materials. There has been very significant work

[a] Dr. Scott M. Lewis, Dr. Antonio Fernandez, Dr George F. S. Whitehead, Agnese Lagzda, Hayden R. Alty, Dr Jesus FerrandoSoria, Dr Sarah Varey, Andreas K. Kostopolous, Dr Christopher A. Muryn, Dr Grigore A, Timco, Prof. Stephen G. Yeates, Prof. Richard E. P. Winpenny

The School of Chemistry, The University of Manchester Oxford Road, Manchester, M13 9PL, United Kingdom

Email: scott.lewis@manchester.ac.uk richard.winpenny@manchester.ac.uk

[b] Dr. Guy A. DeRose, Dr. Matthew S. Hunt, Prof A. Scherer The Kavli Nanoscience Institute, California Institute of Technology, 1200 East California Boulevard, 107 - 81, Pasadena, CA USA 91125

[c] Dr Fredrik Schedin

The National Graphene Institute, The University of Manchester Oxford Road, Manchester M13 9PL, United Kingdom.

Supporting information for this article is given via a link at the end of the document. on creating patterns on surface by self-assembly, e.g. of $\mathrm{H}$ bonded networks ${ }^{13}$ or through coordination chemistry, ${ }^{14}$ but these structures have not then been studied for lithography.

Here we report studies of a complex supramolecular assembly as a resist. To demonstrate the new resist's potential for use with silicon, nanostructures that are $9 \mathrm{~nm}$ wide and $330 \mathrm{~nm}$ high have been fabricated in one write-etch cycle using industrially relevant processes. Such structures resemble Fin-FETs presently being introduced by INTEL.

To design a new resist we have developed Monte Carlo simulations, based on the Joy model, ${ }^{15}$ expanding this approach to incorporate quantum effects using the hard sphere model to consider the low energy electrons $(<500 \mathrm{eV}) .{ }^{16}$ Patterns can be calculated for a putative resist material without any assumptions concerning the underlying chemistry of the resist. The only parameters considered are the molecular weight of the material, the weighted average atomic number of the elements present and the density of the material. Simulations show that to achieve a high resolution the ideal resist would have a high molecular weight and a very low density: together these generate a very large molecular volume. Inclusion of elements with high atomic number improves the speed with which the resist can be written.

Based on these predictions, an excellent candidate is:

$\left[\mathrm{Ni}_{12}(\mathrm{chp})_{12}\left(\mathrm{O}_{2} \mathrm{CMe}\right)_{6}\left(\mathrm{H}_{2} \mathrm{O}\right)_{6}\left\{\left[\mathrm{NH}_{2}{ }^{\mathrm{n}} \mathrm{Pr}_{2}\right]\left[\mathrm{Cr}_{7} \mathrm{NiF}_{8}\left(\mathrm{O}_{2} \mathrm{C}^{\mathrm{t}} \mathrm{Bu}\right)_{15}\left(\mathrm{O}_{2} \mathrm{C}-\right.\right.\right.\right.$ pyridine)] $\}_{6} 1$ (where Hchp = 6-chloro-2-hydroxypyridine; $\mathrm{HO}_{2} \mathrm{C}$ pyridine $=$ iso-nicotinic acid) (Figure 1$).{ }^{17}$

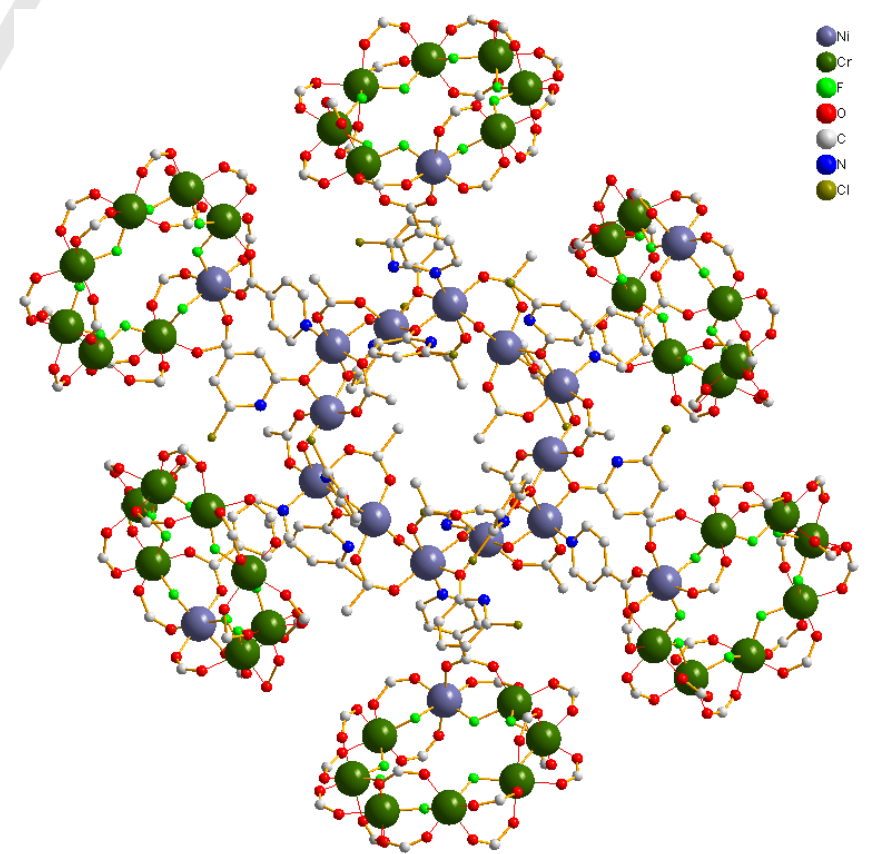

Figure 1. The structure of 1 in the crystal as a ball-and-stick representation. Colours: Ni, light blue; $\mathrm{Cr}$, green; $\mathrm{F}$, yellow; O, red; $\mathrm{N}$, dark blue; $\mathrm{Cl}$, brown; $\mathrm{C}$, grey. $\mathrm{H}$-atoms and $\mathrm{C}$-atoms of t-butyl groups omitted for clarity. 
The compound involves the binding of six octametallic $\left\{\mathrm{Cr}_{7} \mathrm{Ni}\right\}$ rings around a central $\left\{\mathrm{Ni}_{12}\right\}$ ring. The internal structures of the various rings are described in detail elsewhere. ${ }^{17}$ Here we are only concerned with the overall topology. The six octametallic rings pack inefficiently around the central ring, rather like six small plates attached at their edges to one larger central plate. The density of 1 in crystalline form is low $\left(0.81 \mathrm{~g} \mathrm{~cm}^{-3}\right)$ despite the molecular weight of the supramolecule being high (16,887 Dalton). The exterior of 1 consists entirely of $t$-butyl groups, which gives the compound high solubility in solvents suitable for preparing films on silicon substrates.

Compound 1 was deposited on silicon by spin coating from $t$ butylmethyl ether. X-ray photoelectron spectroscopy (XPS) studies show that the films, as deposited, contain intact molecules of 1 (Table S1) and AFM studies show these films are smooth, with a surface roughness $<4 \mathrm{~nm}$, as deposited and after the writing step (see Supplementary Information). The film was written using a $30 \mathrm{KeV}$ e-beam within a scanning electron microscope. After developing the pattern using hexane for 30 seconds we can write $7 \mathrm{~nm}$ lines into a $30 \mathrm{~nm}$ film, separated by $20 \mathrm{~nm}$ (Figure 2a); these match Monte Carlo simulations precisely (Figure 2b).

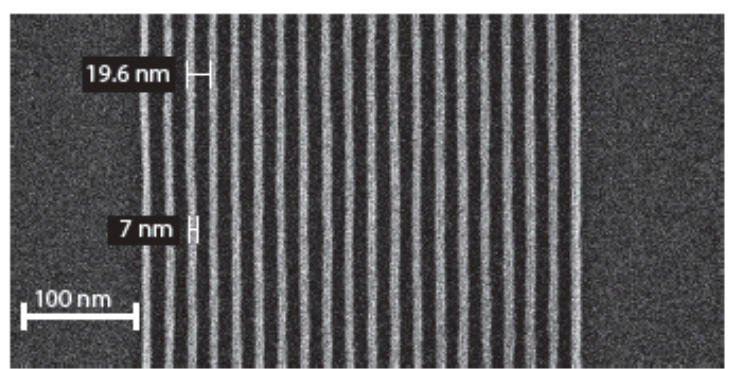

(b)

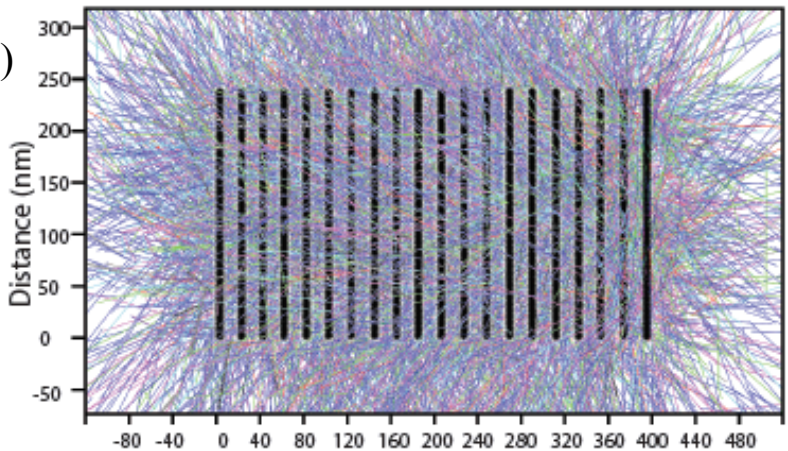

Distance $(\mathrm{nm})$

Figure 2. (a) $7 \mathrm{~nm}$ lines written in 1 using a $30 \mathrm{KeV}$ source at a $20 \mathrm{~nm}$ pitch into a $30 \mathrm{~nm}$ deep film. (b) a Monte Carlo simulation of the performance of 1 under the same conditions. The black lines represent the electrons for the ebeam writer and the red lines are secondary electrons generated from collision with 1 during writing with energies $>500 \mathrm{eV}$. Purple, cyan and green lines are further secondary electrons with associated energies below $500 \mathrm{eV}$ generated by $1^{\text {st }}, 2^{\text {nd }}$ and $3^{\text {rd }}$ order collisions respectively. The blue lines are back scattered electrons.

The pattern written into compound $\mathbf{1}$ has a high selectivity for etching when compared with the silicon substrate (Figure 3). Post writing the material appears to be mainly $\mathrm{Cr}_{2} \mathrm{O}_{3}$, as shown by XPS studies (see Table S2), but doped with fluoride and the second metal. In Figure 3a we show $14 \mathrm{~nm}$ lines written into a $60 \mathrm{~nm}$ thick film of 1. The underlying silicon was then etched with a Pseudo Bosch process that uses an inductively coupled plasma (ICP) of $\mathrm{SF}_{6}$ and $\mathrm{C}_{4} \mathrm{~F}_{8}$ gases. This generates silicon nanostructures that are $14 \mathrm{~nm}$ wide and $155 \mathrm{~nm}$ high; the resist could still be seen at the tip of the silicon structures (Figure $3 b$ ). The resist layer can be removed by wet etching the silicon dioxide $\left(\mathrm{SiO}_{2}\right)$ layer immediately beneath the resist using buffered $\mathrm{HF}$ for
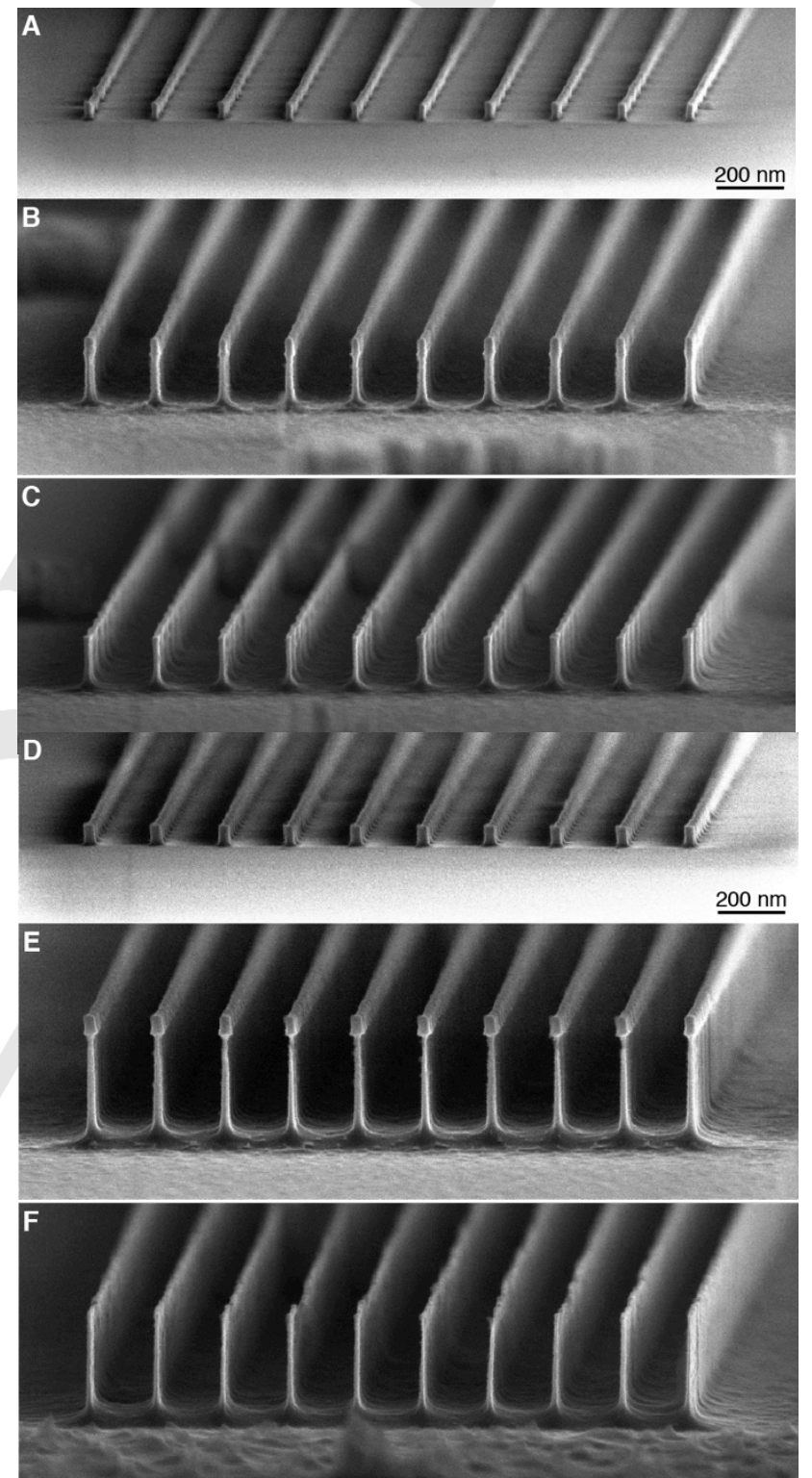

$60 \mathrm{~s}$; doing this yielded silicon fins $155 \mathrm{~nm}$ high and $12 \mathrm{~nm}$ wide (Figure 3c).

Figure 3. a) $14 \mathrm{~nm}$ lines on a $200 \mathrm{~nm}$ pitch written in 1 at $30 \mathrm{KeV}$ and then developed, before the plasma etching process. b) Resist after a 90 second Pseudo Bosch plasma etch process. c) Fins with a $12 \mathrm{~nm}$ width after removal of the resist using buffered hydrofluoric acid. d) $25 \mathrm{~nm}$ lines written in 1 at a 200 $\mathrm{nm}$ pitch, before the plasma etching process. e) Resist after a 210 second Pseudo Bosch plasma etch process, resulting in $10 \mathrm{~nm}$ wide structures. f) Removal of the resist, resulting in $330 \mathrm{~nm}$ tall pillars that are $9 \mathrm{~nm}$ wide.

These etch results are so unusual ${ }^{18}$ they have been pursued further. Firstly, the resist was patterned with a larger line width of 
$25 \mathrm{~nm}$ and a pitch of $200 \mathrm{~nm}$ in a $60 \mathrm{~nm}$ thick film (Figure 3d). The etch time was extended to $210 \mathrm{~s}$ which led to the etch undercutting the resist (Figure 3e); undercutting is normally an undesirable result, but here the final structures are straight with little line edge roughness. The remaining resist was $58 \mathrm{~nm}$ high and can be seen at the tip of the silicon fins (Figure $3 \mathrm{e}$ ). This gives a resist etch rate of $0.12 \mathrm{~nm} \mathrm{~s}^{-1}$ while the silicon etch rate was $1.55 \mathrm{~nm} \mathrm{~s}^{-1}$. The silicon has etched 130 times faster than the resist, which is a selectivity twice as good as the best observed previously (with aluminium oxide masks) ${ }^{12 b}$ Removal of the resist gives silicon nanostructures with a $330 \mathrm{~nm}$ height and $9 \mathrm{~nm}$ width, i.e. a 36:1 aspect ratio in one write-etch cycle (Figure 3f).

The process generates silicon structures almost three times narrower than the resist pattern written by the e-beam (compare Figures $3 d$ and $3 f$ ). To our knowledge such behavior is unprecedented and is caused by the huge resistance of structures written in $\mathbf{1}$ to the plasma etch process. Most of the resist remains after etching for 210 seconds (Figure $3 \mathrm{e}$ ). The resist is therefore capable of surviving for longer etch times; in the future we will examine the maximum depth of etch that can be achieved. The targets are large area patterns etched containing structures that are much taller than the $330 \mathrm{~nm}$ fins shown here.

Use of a large supramolecular assembly such as $\mathbf{1}$ demonstrates a potentially new area to be explored using supramolecular chemistry. Our studies of $\mathbf{1}$ are the most complete, however we have studied many related compounds in this context. These include: individual heterometallic rings such as $\left[\mathrm{NH}_{2} \mathrm{Pr}_{2}\right]\left[\mathrm{Cr}_{7} \mathrm{NiF}_{8}\left(\mathrm{O}_{2} \mathrm{CR}\right)_{16}\right]\left(\mathrm{R}={ }^{\mathrm{t}} \mathrm{Bu} 2\right.$ or $-\mathrm{CH}(\mathrm{Me})-\mathrm{CH}_{2}-\mathrm{CH}=\mathrm{CH}_{2}$ 3) ${ }^{19}$ a [7]rotaxane containing six heterometallic rings around a central oxo-centered metal triangle $4 ;{ }^{20}$ and an $8 \mathrm{~nm}$ molecular nanoparticle containing 24-heterometallic rings around a $\left\{\mathrm{Pd}_{12}\right\}$ cuboctahedron 5 . $^{21}$ We find all are suitable as electron beam resists, but that the larger compounds $\mathbf{1 , 4}$ and $\mathbf{5}$ are better for high resolution structures (Figure S3). For example, $8 \mathrm{~nm}$ lines are easily written into $\mathbf{5}$. We believe this is because the electron beam is writing into a molecular material and most scattering events occur when the beam hits an individual molecule. This event occurs far more rarely for a very large molecule than a small molecule, and hence the scattering is lower for large molecules and resolution is concomitantly higher. We compared $\mathbf{2}$ with $\mathbf{3}$ to examine whether simpler chemical engineering of performance was possible: we find that the unsaturated side-chain on the carboxylate in $\mathbf{3}$ leads to a resist that writes more quickly, but where we lose resolution.

In all cases XPS studies shows that material is based on $\mathrm{Cr}_{2} \mathrm{O}_{3}$ post writing, and it is this that gives the extreme etch selectivity. Therefore we can conclude that etch performance is due to the presence of the early d-block metal in the initial resist.

These initial studies show we can design a material with a combination of unique and potentially transformative properties in an area of immediate technological relevance. The processes applied are typical of those used in industry with polymeric resists, and silicon structures can be produced with an aspect ratio greater than 30:1. The key chemical features are: a low density but high molecular weight material - these are the parameters that allow high resolution features to be written; decomposition in the e-beam to a hard material - in this case $\mathrm{Cr}_{2} \mathrm{O}_{3}$ - which is strongly resistant to the etching plasma; solubility in the solvents - mainly non-polar organic solvents - used in the semiconductor industry. Considering examples where these key features are combined it is apparent, that many metallosupramolecular compounds could be useful, for example metal capsules made by the Fujita group are hollow and hence low density. ${ }^{22}$ Possibly the most unusual feature of $\mathbf{1}-\mathbf{5}$ is actually the high solubility in suitable solvents, and hence their processability.

Other new routes to nanometer lithographed structures are being explored. An interesting comparison is with direct laser writing of nanostructures. ${ }^{23,24}$ This alternative approach has huge flexibility and greater speed than we can achieve at present due to the advantage of laser writing rather than e-beam writing. However, the resulting materials are organic polymers and, as with other polymeric resist materials, ${ }^{18}$ are unlikely to demonstrate the extreme etch selectivity of 1 . The array of new techniques ${ }^{13,14,23}$ being developed to pattern surfaces and nanostructures should be regarded as complementary, and possible routes forward to make still smaller nanodevices in the future. ${ }^{8}$

\section{Acknowledgements}

We acknowledge the EPSRC(UK) for funding (grant EP/L018470/1) including a studentship within the Centre for Doctoral Training "NoWNANO" (to SV) and a Doctoral Prize (to GFSW). The University of Manchester also supported this work. The authors gratefully acknowledge critical support and infrastructure provided for this work by the Kavli Nanoscience Institute at Caltech.

Keywords: lithography; supramolecular assembly; heterometallic

[1] "The Nobel Prize in Chemistry 2016". Nobelprize.org. Nobel Media AB 2016.

[2] J. E. Green, J. W. Choi, A. Boukai, Y. Bunimovich, E. Johnston-Halpern, E. Delonno, Y. Luo, B. A. Sheriff, K. Xu, Y. S. Shin, H. -R. Tsong, J. F. Stoddart and J. R. Heath, Nature 2007, 445, 414.

[3] B. Lewandowski, G. De Bo, J. W. Ward, M. Papmeyer, S. Kuschel, M. J. Aldegunde, P. M. E. Gramlich, D. Heckmann, S. M. Goldup, D. M. D'Souza, A. E. Fernandes, D. A. Leigh, Science 2013, 339, 189-193.

[4] D. Zhao, T. van Leeuwen, J. Cheng, B. L. Feringa, Nature Chem.2016 doi: $10.1038 /$ nchem. 2668 .

[5] M. Urdampilleta, S. Klyatskay, J. -P. Cleuziou, M. Ruben, W. Wernsdorfer, Nature Materials 2011, 10, 502.

[6] (a) U. Okoroanyanwu, Chemistry and Lithography. SPIE Press, Washington 2011. (b) C. A. Mack, Fundamental Principles of Optical Lithography: The Science of Microfabrication, John Wiley \& Sons, London, 2007.

[7] M. J. Rooks, E. Kratschmer, R. Viswanathan, J. Katine, R. E. Fontana Jr., S. A. MacDonald, J. Vac. Sci. Technol. B. 2002, 20, 2937.

[8] International Roadmap for Semiconductors 2.0 ITRS 2015.

[9] A. E. Grigorescu, C. W. Hagen, Nanotechnology, 2009, 20, 292001.

[10] A. Frommhold, J. Manyam, R. E. Palmer, A. P. G. Robinson, Microelectron. Engn. 2012, 98, 552.

[11] L. Merhari, K. E. Gonsalves, Y. Hu, W. He, W. -S. Huang, M. Angelopoulos, W. H. Bruenger, C.Dzionk, M. Torkler Microelectron. Engn. 2002, 63, 391.

[12] (a) Z. Huang, N. Geyer, P. Werner, J. de Boor, U. Gösele, Adv. Mater. 2011, 23, 285. (b) D. Henry, S. Walavalkar, A.Homyk, A. Scherer, Nanotechnology 2009, 20, 2555305. 
[13] J. A. Theobald, N. S. Oxtoby, M. A. Phililps. N. R. Champness, P. H. Beton, Nature 2003, 424, 1029.

[14] U. Schlickum, R. Decker, F. Klappenberg, G. Zoppellaro, S. Klyatskaya, M. Ruben, I. Silanes. A. Arnau, K. Kern, H. Brune, J. V. Barth, Nano Lett. 2007, 7, 3813

[15] D. C. Joy, Monte Carlo Modeling for Electron Microscopy and Microanalysis. Oxford University Press, New York 1995.

[16] S. M. Lewis, G. A. DeRose. SML electron beam resist: ultra-high aspect ratio nanolithography in Frontiers of Nanoscience, Materials and Processes for Next Generation Lithography, 2016, 11, 421.

[17] G. F. S. Whitehead, F. Moro, G. A. Timco, W. Wernsdorfer, S. J. Teat, R. E. P. Winpenny, Angew. Chem. Int. Ed. 2013,52, 9932.

[18] A. Goodyear, M. Boettcher, I. Stolberg, M. Cooke, Proc. SPIE 2015 9428, 94280V.

[19] E. J. L. McInnes, G. A. Timco, G. F. S. Whitehead and R. E. P. Winpenny, Angew. Chem. Int. Ed., 2015, 54, 14244 and refs therein.
[20] A. Fernandez, J. Ferrando-Soria, E. M. Pineda, F. Tuna, I. J. VitoricaYrezabal, C. Knappke, J. Ujma, C. A. Muryn, G. A. Timco, P. E. Barran, A. Ardavan, R. E. P. Winpenny, Nat. Commun., 2016, 7, 10240

[21] J. Ferrando-Soria, A. Fernandez, E. M. Pineda, S. A. Varey, R. W. Adams, I. J. Vitorica-Yrezabal, F. Tuna, G. A. Timco, C. A. Muryn, R. E. P. Winpenny, 2015, 137, 7644

[22] Y. Inokuma, M. Kawano, M. Fujita, Nature Chem. 2011, 3, 349.

[23] M. Deubel, G. von Freymann, M. Wegener, S. Pereira, K. Busch, C. M. Soukoulis, Nature Materials, 2004, 3, 444.

[24] E. Blasco, M. Wegener, C. Barner-Kowollik, Adv. Materials, 2017, DOI: 10.1002/adma.201604005. 
Entry for the Table of Contents (Please choose one layout)

\section{COMMUNICATION}

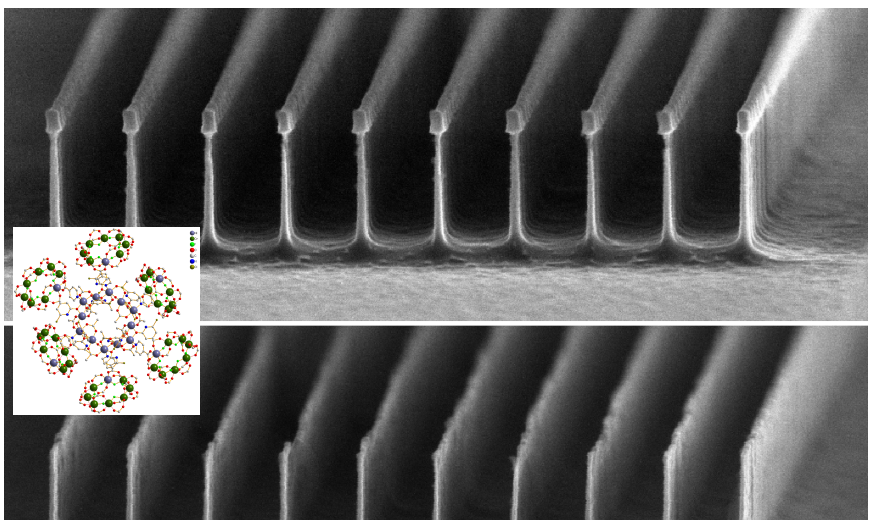

Scott M. Lewis, Antonio Fernandez, Guy

A. DeRose, Matthew S. Hunt, George F.

S. Whitehead, Agnese Lagzd, Hayden

R. Alty, Jesus Ferrando-Soria, Sarah

Varey, Andreas K. Kostopoulos, Fredrik

Schedin, Christopher A. Muryn, Grigore

A. Timco, Axel Scherer, Stephen G.

Yeates and Richard E. P. Winpenny

Page No. - Page No.

Use of Supramolecular Assemblies as Lithographic Resists 